\title{
Lithium enhances the antitumour effect of temozolomide against TP53 wild-type glioblastoma cells via NFAT1/FasL signalling
}

\author{
Sheng Han ${ }^{1}$, Lingxuan Meng ${ }^{1}$, Yang Jiang ${ }^{1}$, Wen Cheng ${ }^{1}$, Xinxin Tie ${ }^{1}$, Junzhe Xia ${ }^{1}$ and Anhua Wu ${ }^{*, 1}$ \\ ${ }^{1}$ Department of Neurosurgery, The First Hospital of China Medical University, Nanjing Street 155, Heping District, Shenyang \\ 110001, China
}

Background: We previously showed that activation of the nuclear factor of activated T cells (NFAT)1/Fas ligand (FasL) pathway induces glioma cell death. Lithium (Li) is an inhibitor of glycogen synthase kinase (GSK)-3 that activates NFAT1/FasL signalling. Temozolomide (TMZ) inhibits GSK-3 and activates Fas in tumour protein (TP)53 wild-type (TP53wt) glioma cells. The present study investigated the combinational effects of TMZ and low-dose Li on TP53wt glioma cells.

Methods: The combined effect of TMZ and Li was examined in TP53wt U87 and primary glioma cells and a mouse xenograft model.

\begin{abstract}
Results: Combination with $1.2 \mathrm{~mm}$ Li potentiated TMZ-induced cell death in TP53wt glioma cells, as determined by neurosphere formation and apoptosis assays. Temozolomide combined with Li treatment inhibited GSK-3 activation, promoted NFAT1 nuclear translocation and upregulated Fas/FasL expression. Targeted knockdown of NFAT1 expression blocked the induction of cell death by TMZ and Li via FasL inhibition. In vivo, combined treatment with TMZ and Li suppressed tumour growth and prolonged the survival of tumour-bearing mice. However, the combination of TMZ and Li did not produce a statistically significant effect in TP53mut glioma cells.
\end{abstract}

Conclusions: Temozolomide combined with low-dose Li induces TP53wt glioma cell death via NFAT1/FasL signalling. This represents a potential therapeutic strategy for TP53wt glioma treatment.

Glioblastoma (GBM) is the most common and lethal primary brain tumour in adults. Currently, the most effective treatment strategy for newly diagnosed GBM is surgical resection followed by radiotherapy and temozolomide (TMZ) chemotherapy (Stupp et al, 2005). However, the median overall survival is only 14.6 months; treatment failures often result from the development of TMZ chemoresistance, which is mediated by multiple signalling pathways (Han et al, 2014; Vo et al, 2014). Genetic and epigenetic factors - especially tumour protein (TP) 53 and $O^{6}$-methylguanine DNA methyltransferase (MGMT) - determine the sensitivity of glioma to TMZ and consequent apoptosis (Roos et al, 2007). To increase the therapeutic efficacy of TMZ, the mechanism of TMZ- induced glioma cell death must be clarified so that it can serve as a basis to develop new treatment approaches.

We previously demonstrated that nuclear factor of activated T cells (NFAT) 1 is highly expressed in GBM cells (Tie et al, 2013). Moreover, hyper-activation of NFAT1 leads to the upregulation of FasL and induces GBM cell death in a manner similar to activation-induced cell death (AICD) in mature lymphocytes (Han et al, 2013). The activation and nuclear translocation of NFATs are inhibited by glycogen synthase kinase (GSK)-3 (Crabtree and Olson, 2002). Therefore, targeting GSK-3 and NFAT1 activity to induce an AICD-like process in gliomas is a novel approach to GBM treatment.

*Correspondence: Dr A Wu; E-mail: cmuwuanhua1@yahoo.com

Received 1 March 2017; accepted 10 March 2017; published online 30 March 2017

C) 2017 Cancer Research UK. All rights reserved 0007 - 0920/17 
Lithium ( $\mathrm{Li}$ ) has long been used for the clinical treatment of mood disorders (Kovacsics et al, 2009). Li directly inhibits GSK-3 and activates the NFAT1/FasL-mediated apoptosis pathway in many cell types (Gomez-Sintes and Lucas, 2010; Ayton and Lei, 2012). It was recently reported that $\mathrm{Li}$ concentrations $>5 \mathrm{~mm}$ can affect the proliferation, apoptosis and migration of glioma cells via GSK-3 inhibition (Nowicki et al, 2008; Chou et al, 2012; Fu et al, 2014; Aras et al, 2016). However, the therapeutic window of Li is $0.6-1.4 \mathrm{~mm}$, and serum levels $>1.5 \mathrm{~mm}$ are correlated with progressive toxicity, ultimately leading to neurological impairment (Young, 2009; Gomez-Sintes and Lucas, 2010). As such, administering high doses of $\mathrm{Li}$ is unfeasible, while lowering the therapeutic dose remains a clinical challenge.

Temozolomide has been shown to activate AKT (Vo et al, 2014; Yu et al, 2015), leading to the phosphorylation and deactivation of GSK-3 in glioma cells (Vo et al, 2014), which could further activate NFATs. Moreover, TMZ triggers apoptosis in TP53 wild type and mutant (TP53wt and TP53mut, respectively) glioma cells. In the former, Fas receptor is activated and induces cell death in response to TMZ treatment in contrast to TP53mut cells (Roos et al, 2007). We therefore speculated that TMZ combined with a low dose of $\mathrm{Li}$ could hyperactivate NFAT1/FasL signalling via GSK-3 inhibition. We investigated this possibility in the present study using TP53wt GBM cells and in a mouse xenograft model of GBM.

\section{MATERIALS AND METHODS}

Cell culture. Human TP53wt U87 and TP53mut U251 GBM cells with methylated MGMT promoters (Li et al, 1999; Dinca et al, 2008; Han et al, 2014; Chen et al, 2016) were purchased from the Chinese Academy of Sciences cell bank (Shanghai, China). U87 cells have wild-type isocitrate dehydrogenase (IDH) with a mutated telomerase reverse transcriptase (TERT) promoter and contain 1p19q co-deletion. U251 cells are IDH wild type with a mutated TERT promoter and non-1p19q co-deletion. Molecular features of U87 and U251 cells were determined by GenomiCare Biotechnology (Shanghai, China) and are consistent with previous reports (Law et al, 2005; Wu et al, 2013; Johanns et al, 2016). Primary G1 and G2 GBM cells were derived from fresh clinical samples obtained from a 72-year-old female and a 54-year-old male GBM patient, respectively. G1 and G2 cell lines were established and neurosphere culture was performed as previously described by our group (Han et al, 2015). Tumour samples were analysed by Sanger sequencing and pyrosequencing (YuanQi Bio, Shanghai, China). G1 cells were TP53wt with an unmethylated MGMT promoter and G2 cells were TP53mut with an unmethylated MGMT promoter. In addition, both G1 and G2 cells were IDH wild type with a mutated TERT promoter and non-1p19q co-deletion. Molecular parameters of these GBM cells are described in Supplementary Table S1. This study was approved by the institutional review board of our hospital, and written informed consent was obtained from each glioma tissue donor, who consented to the use of the tumour tissue and clinical data for future research.

Cells were cultured in Dulbecco's modified Eagle's medium supplemented with $10 \%$ fetal bovine serum ( Invitrogen, Carlsbad, CA, USA) and antibiotics (penicillin and streptomycin, $100 \mathrm{U} \mathrm{ml}^{-1}$ each) at $37^{\circ} \mathrm{C}$ and $5 \% \mathrm{CO}_{2}$.

Cell viability assay. Cells were seeded in 96-well plates at a density of $1 \times 10^{4}$ cells per well. The following day, cells were subjected to serum starvation overnight, and then treated with $1.2 \mathrm{~mm}$ $\mathrm{LiCl}$ (Sigma-Aldrich, St Louis, MO, USA) and/or $70 \mu \mathrm{M} \mathrm{TMZ}$ (Sigma-Aldrich) for 24, 48, 72 or $96 \mathrm{~h}$. In a subset of cultures, cells were pre-incubated with $10 \mu \mathrm{g} \mathrm{ml}^{-1}$ FasL-neutralising antibody (AF126; Research Diagnostics, Flanders, NJ, USA) for $24 \mathrm{~h}$ before $\mathrm{TMZ}+\mathrm{Li}$ administration. The 3-(4,5-dimethylthiazol-2-yl)-2, 5-diphenyltetrazolium (MTT) assay was used to evaluate cell proliferation according to the manufacturer's protocol. Cells were also quantified by cell counts using a haemocytometer after trypan blue staining.

Neurosphere formation assay. Cells were dissociated from neurospheres and seeded at 200 cells per well in 24-well plates and treated or left untreated as described above, and then cultured under neurosphere conditions for 7 days. Formed neurospheres were counted and are reported as the percentage of neurosphereforming cells out of the total number of cells (i.e., 200). Neurospheres were immunolabelled with an anti-CD133 antibody (1 : 100, 293C3; Miltenyi Biotec, Auburn, CA, USA).

Detection of apoptosis by flow cytometry. To evaluate the subG0 DNA content, cells were stained with propidium iodide (PI, $75 \mu \mathrm{M}$ ) in PBS containing $0.1 \%$ Nonidet P-40. DNA content was determined by flow cytometry using a FACScalibur instrument and CellQuest software (BD Biosciences, San Jose, CA, USA). The percentage of apoptotic cells was also determined with a fluorescein isothiocyanate-Annexin V Apoptosis Detection kit (BD Biosciences) according to the manufacturer's instructions.

Terminal deoxynucleotidyl transferase dUTP nick end labelling assay. Apoptotic cells were detected by terminal deoxynucleotidyl transferase dUTP nick end labelling (TUNEL) using the TdTFragEL DNA Fragmentation Detection kit (QIA33; Merck, Darmstadt, Germany) according to the manufacturer's instructions. Terminal deoxynucleotidyl transferase dUTP nick end labelling-positive cells were counted under an epifluorescence microscope. Cells with green fluorescence were defined as apoptotic and the rate of apoptosis was calculated according to the following formula: positive cells/(positive cells + negative cells) $\times 100 \%$.

Transmission electron microscopy analysis. Cells were fixed with $2.5 \%$ glutaraldehyde, washed and post-fixed in osmium tetroxide. Samples were dehydrated in a graded series of ethanol, stained with uranyl acetate and embedded in culture dishes. Ultra-thin sections of the cured blocks were cut using a diamond knife, and sections were stained with lead citrate and visualised by a transmission electron microscope (1200-EX; JEOL, Tokyo, Japan).

Western blotting. Total protein was extracted from cells using lysis buffer. To assess NFAT1 nuclear translocation, cytoplasmic and nuclear fractions were prepared as previously described (DiazMeco et al, 1999; Gomez-Sintes and Lucas, 2010). Equal amounts of protein from each sample were separated by electrophoresis and transferred to a nitrocellulose membrane, which was blocked and incubated overnight at $4{ }^{\circ} \mathrm{C}$ with antibodies against GSK-3 $\alpha / \beta$ (D75D3; Cell Signaling Technology, Beverly, MA, USA), pSer21/9GSK-3 $\alpha / \beta$ (D17D2; Cell Signaling Technology), p53 (ab1101; Abcam, Cambridge, UK), Fas (ab103551; Abcam), NFAT1 (ab2722; Abcam) and FasL (all at 1:1000 dilution). The membrane was then incubated with the appropriate secondary antibody. Protein bands were detected using an enhanced chemiluminescence kit (Santa Cruz Biotechnology, Santa Cruz, CA, USA) and band intensity was quantified using Sigma-Gel software (Jandel Scientific Software, Sari Kafael, CA, USA).

Immunocytochemistry. Cells grown on coverslips were washed, fixed, blocked and incubated with an antibody against NFAT1 $(1: 100)$. Following treatment with a fluorophore-conjugated secondary antibody and nuclear counterstaining with Hoechst 33342 , the coverslips were mounted on glass slides and cells were visualised and imaged with a confocal microscope (Olympus FV1000S-SIM; Olympus, Tokyo, Japan).

NFAT1 and p53 gene knockdown. Short hairpin (sh)RNAmediated gene knockdown was carried out as previously described 
(Han et al, 2013; Tie et al, 2013). A plasmid encoding shRNAs targeting NFAT1 or p53 or a control shRNA plasmid (Santa Cruz Biotechnology) was transfected into U87 and G1 cells; 48 h later and after puromycin selection $\left(5 \mu \mathrm{g} \mathrm{ml}^{-1}\right)$, cells stably expressing NFAT1- or p53-shRNA were identified and used for experiments.

Real-time reverse transcription (RT)-PCR. Primers for amplifying NFAT1 and FasL are shown in Supplementary Table S2. Total RNA (200-500 ng) from each sample was used to synthesise cDNA, which was used as a template for PCR. Reactions were prepared in triplicate and the conditions were as follows: $95^{\circ} \mathrm{C}$ for $3 \mathrm{~min}$, followed by 45 cycles of $95^{\circ} \mathrm{C}$ for $20 \mathrm{~s}, 63^{\circ} \mathrm{C}$ for $20 \mathrm{~s}$ and $72^{\circ} \mathrm{C}$ for $20 \mathrm{~s}$.

Tumour xenograft model. Female 6-week-old nude BALB/C mice were purchased from the Institute of Laboratory Animal Sciences (CAMS and PUMC, Beijing, China). Animal experiments were conducted in accordance with the China Medical University Animal Ethics Committee guidelines and approved by the Institutional Review Board of our hospital.

U87 cells $\left(5 \times 10^{4}\right.$ in $5 \mu$ l of PBS) were injected intracranially in anaesthetised nude mice. After 10 days, mice with similar tumour bioluminescence were selected and divided into treatment and control groups ( $n=8$ per group) and were administered $\mathrm{Li}_{2} \mathrm{CO}_{3}$ (220 $\mathrm{mg} \mathrm{kg}^{-1} \mathrm{day}^{-1}$, per o.s.; Sigma-Aldrich) and/or TMZ $\left(10 \mathrm{mg} \mathrm{kg}^{-\mathrm{g}} \mathrm{day}^{-1}\right.$, per o.s.). Control animals were treated with vehicle. Blood Li levels were analysed weekly, and stabilised at 1.0-1.2 $\mathrm{mm}$ on day 5 after administration. Mice were killed using Euthasol $\left(0.22 \mathrm{ml} \mathrm{kg}^{-1}\right.$ i.v.; Delmarva Laboratories, Midlothian, VA, USA) when they exhibited signs of distress.

For subcutaneous tumour models, $1 \times 10^{6} \mathrm{G} 1$ cells in $50 \mu \mathrm{l}$ of PBS were subcutaneously injected into the left flank of anaesthetised nude
A
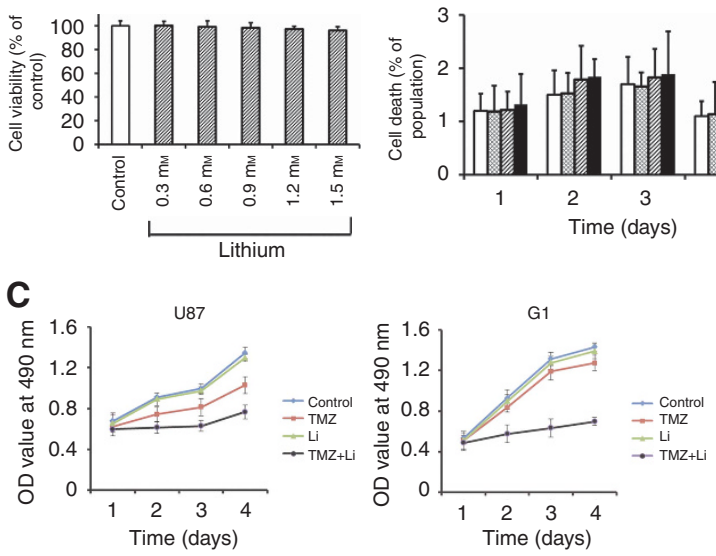

E
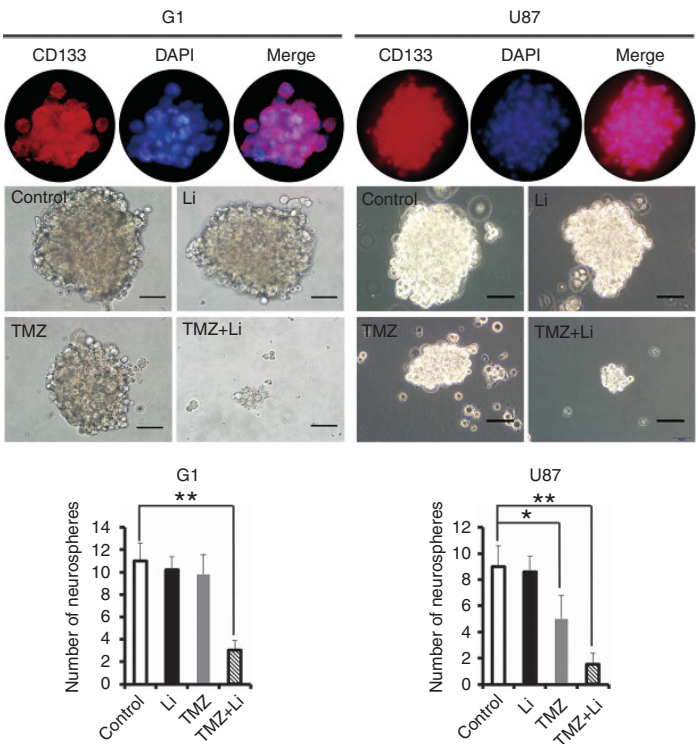

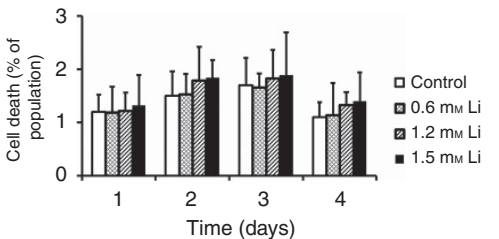

D

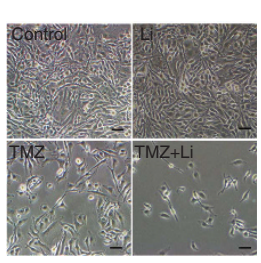

$\mathbf{F}$

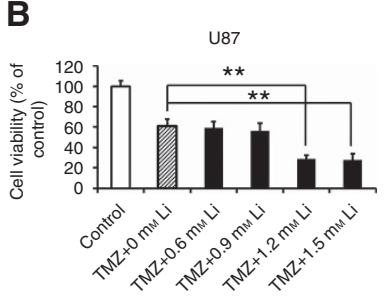

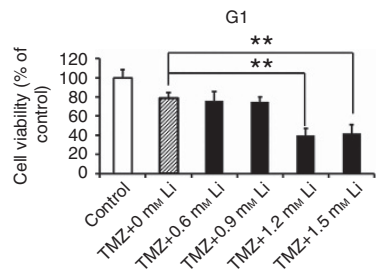
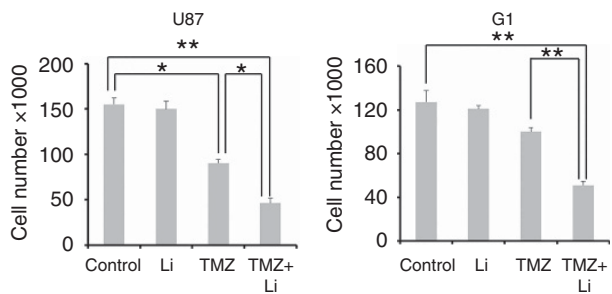
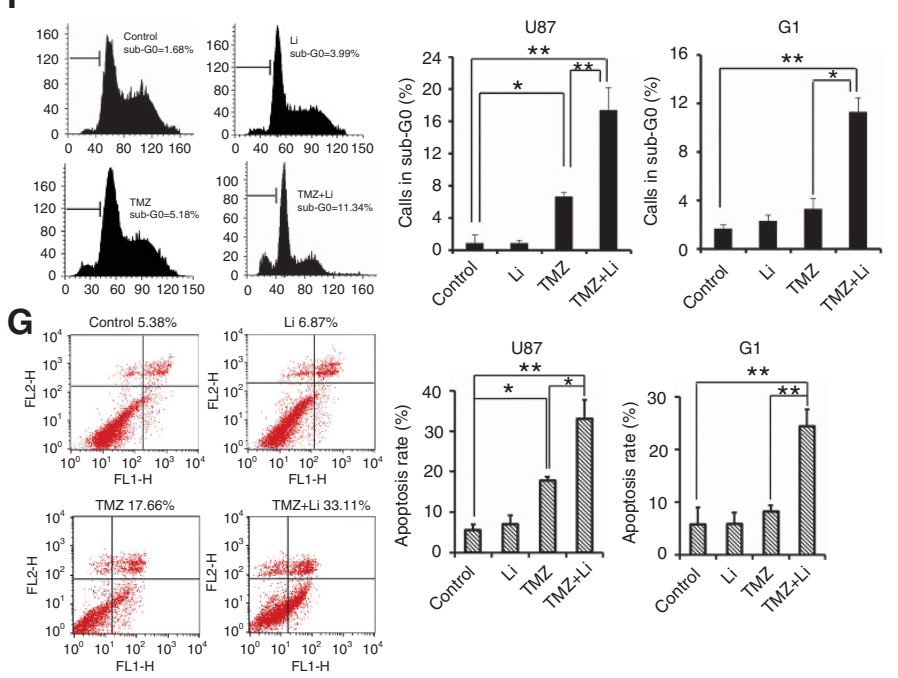

Figure 1. Temozolomide combined with Li decreases TP53wt GBM cell viability and inhibits proliferation. (A) U87 cell viability in the presence of increasing $\mathrm{Li}$ concentrations at $48 \mathrm{~h}$, as determined with the MTT assay (left). Cell death was detected by propidium iodide staining and flow cytometry analysis in U87 cells treated with indicated Li concentrations for indicated times (right). (B) U87 and G1 cell viability in the presence of $70 \mu \mathrm{M} T M Z$ combined with different concentrations of $\mathrm{Li}$ at $48 \mathrm{~h}$, as determined with the MTT assay. GBM cells were left untreated or were treated with TMZ $(70 \mu \mathrm{M})$, $\mathrm{LiCl}(1.2 \mathrm{mM})$ or TMZ + Li. (C) Viability of U87 and $\mathrm{G} 1$ cells as determined by the MTT assay at indicated time points. (D) Representative micrographs of U87 cells (left). Scale bar $=50 \mu \mathrm{m}$. Cell counts following $48 \mathrm{~h}$ treatment with $\mathrm{TMZ}, \mathrm{LiCl}$ or TMZ $+\mathrm{Li}$ (right). (E) Neurospheres of U87 and G1 cells were labelled with an antibody against the glioma stem cell (GSC) marker CD133. U87 and G1 GSCs were grown under neurosphere culture conditions in the absence or presence of $\mathrm{TMZ}(70 \mu \mathrm{M}), \mathrm{LiCl}(1.2 \mathrm{mM})$ or $\mathrm{TMZ}+\mathrm{Li}$ for 7 days and the number of neurospheres was counted. Upper: representative images of $\mathrm{G} 1$ and U87 neurospheres. (F) Analysis of cell death by flow cytometry $48 \mathrm{~h}$ after treatment. The fraction of cells in sub-G0 is shown in the graphs. (G) Cells were labelled with fluorescein isothiocyanate-conjugated annexin-V and analysed by flow cytometry. Graphs (left) showing annexin- $V$ staining of U87 cells are representative of three independent experiments. Results are presented as mean \pm s.e., of triplicate samples from three independent experiments. ${ }^{\star} P<0.05,{ }^{\star \star} P<0.01$. 
A

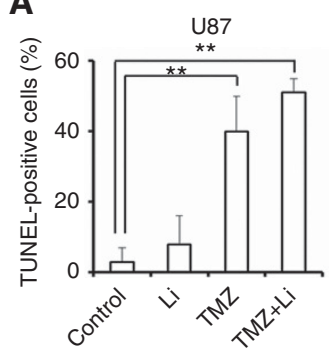

C

U87

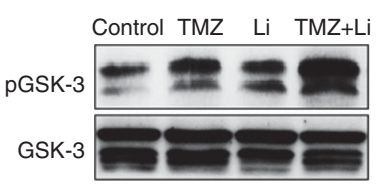

G1

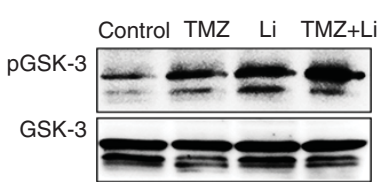

E

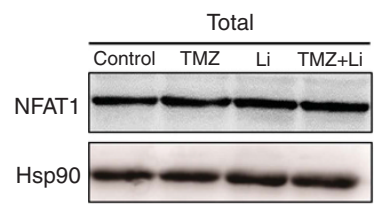

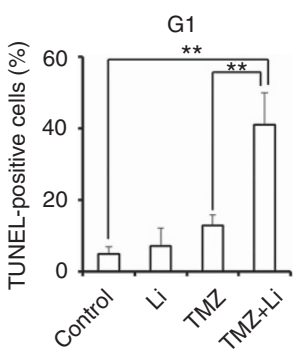
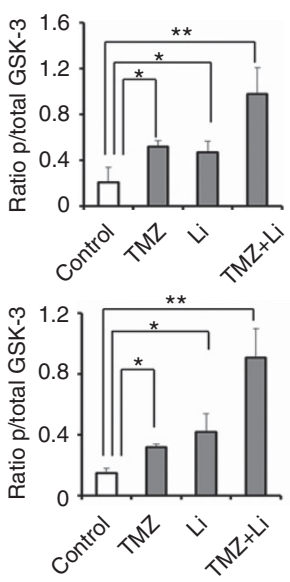

B

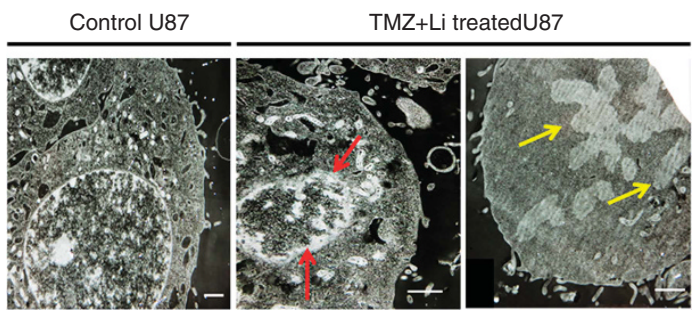

D

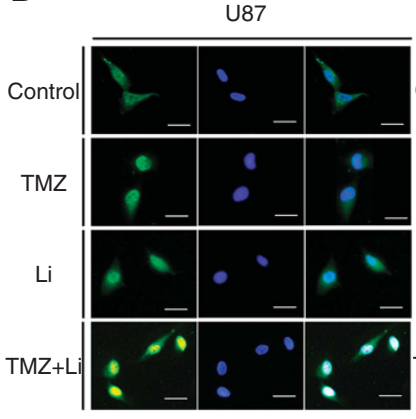

G1

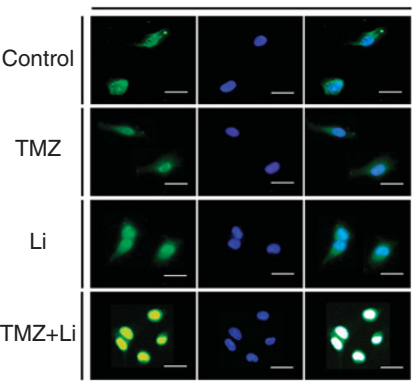

G

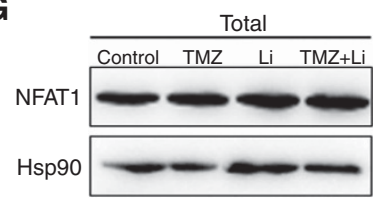

I

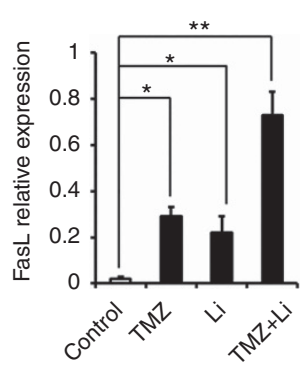

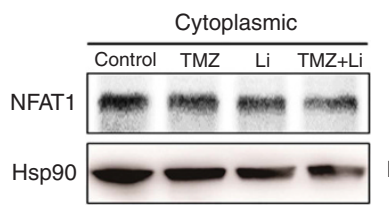

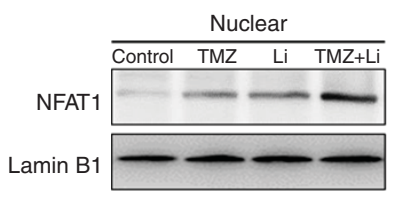

F
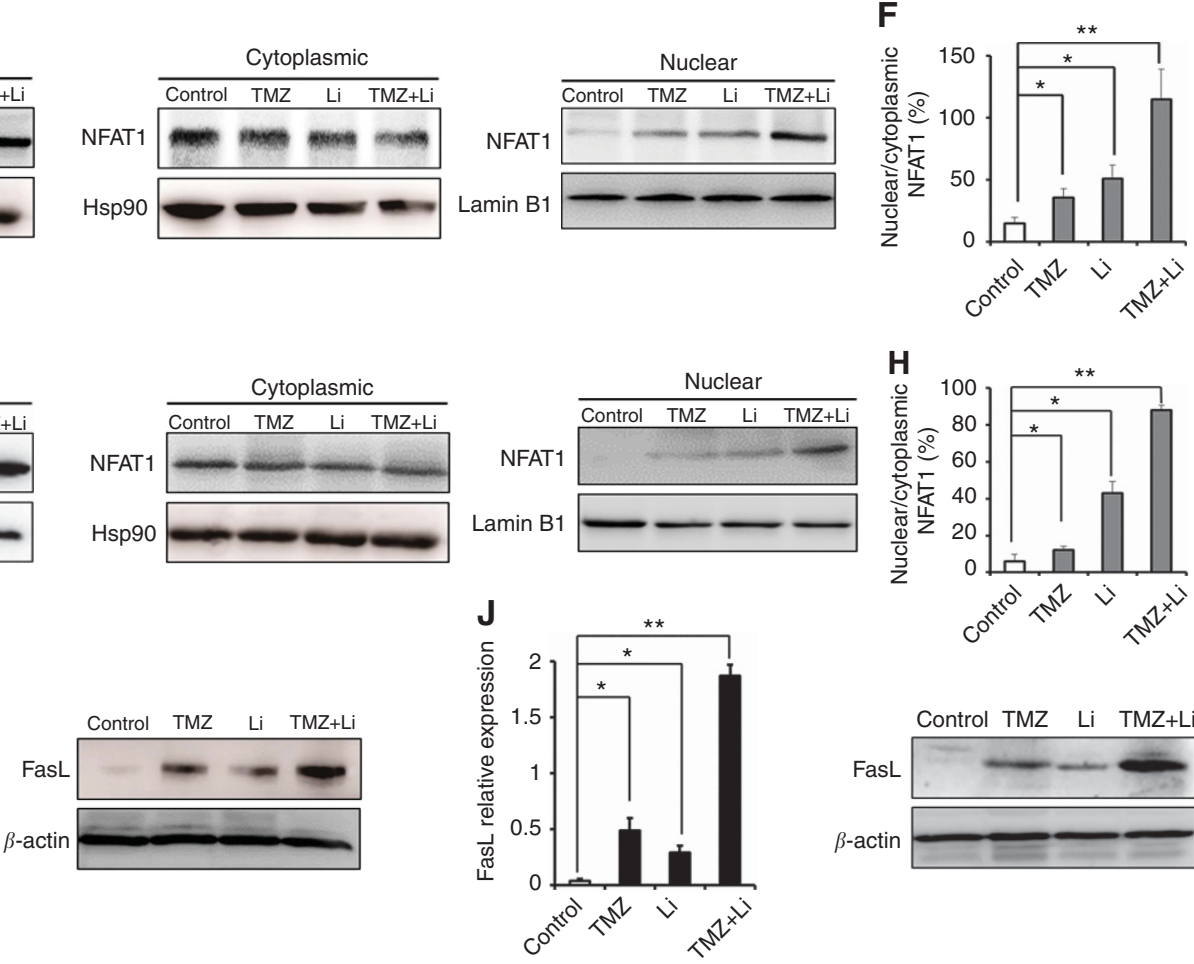

Figure 2. Combining TMZ and Li reduces GSK-3 activity, promotes nuclear translocation of NFAT1 and induces FasL expression and cell death in TP53wt GBM cells. (A) TUNEL assay for detection and quantification of apoptotic cells after $48 \mathrm{~h}$ of treatment with $\mathrm{TMZ}(70 \mu \mathrm{M})$, LiCl (1.2 mM) or $\mathrm{TMZ}+\mathrm{Li}$ in U87 and G1 cells. (B) Representative transmission electron micrographs of U87 cells left untreated or treated with TMZ + Li for $48 \mathrm{~h}$. Transmission electron microscopy was used to evaluate morphological changes in U87 cells after TMZ + Li treatment. Drug treatment altered the nuclear morphology and caused chromatin condensation (red arrows) and nuclear fragmentation (yellow arrows) in U87 cells, consistent with dying cells. Scale bar $=1 \mu \mathrm{m}$. (C) Western blot (left) and quantitative (right) analyses of inactive GSK-3 (pSer21/9-GSK-3 $\alpha / \beta$ ) in U87 and G1 cells treated with TMZ, LiCl or TMZ + Li. (D) Representative confocal micrographs showing NFAT1 expression in U87 and G1 cells, as detected by immunocytochemistry. Nuclei were counterstained with Hoechst 33342. Scale bar $=25 \mu \mathrm{m}$. (E-H) Western blot analysis of NFAT1 in total, cytoplasmic and nuclear protein fractions from control or treated U87 (E) and G1 (G) cells. Hsp90 and lamin B1 were used as loading controls for the cytoplasmic and nuclear fractions, respectively. The nuclear/cytoplasmic ratio of NFAT1 in U87 (F) and G1 (H) cells are shown. (I, J) FasL mRNA and protein expression, as determined by real-time RT-PCR (left) and western blotting (right), respectively, in control or treated U87 (I) and G1 (J) cells. Graphs show mean values of triplicate samples from three independent experiments. ${ }^{\star} P<0.05,{ }^{\star \star} P<0.01$. 
A
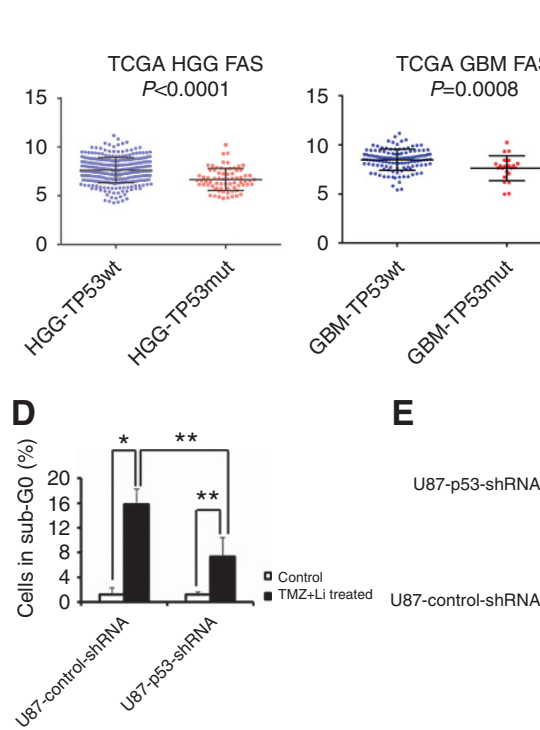

B

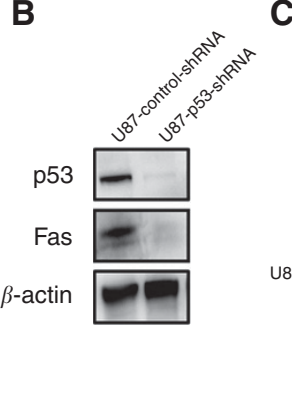

C
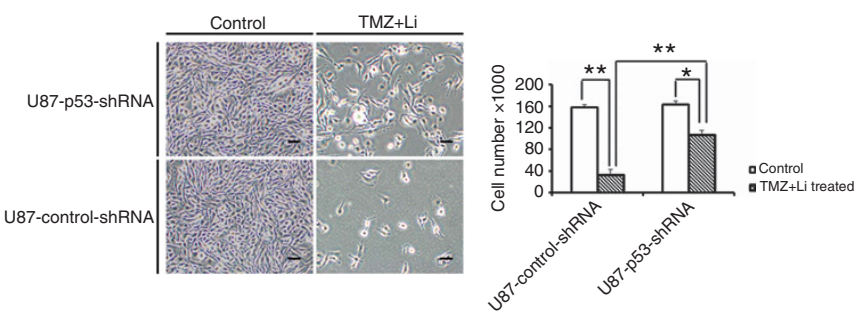

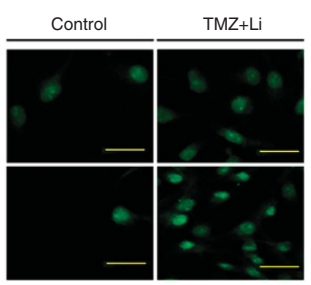

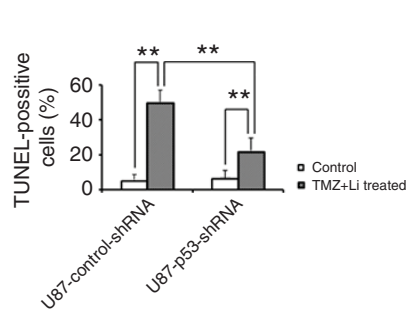

$\mathbf{F}$
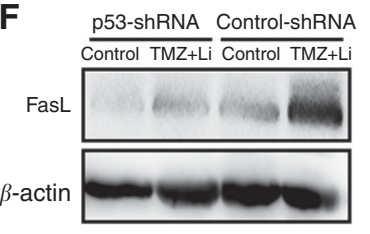

Figure 3. TP53 status influences TMZ + Li-induced apoptosis. (A) Fas expression as reported in TCGA was compared between TP53wt and TP53mut glioma. HGG, high-grade glioma. (B) Loss of p53 expression by shRNA-mediated knockdown in U87 cells and consequent downregulation of Fas expression, as determined by western blotting. (C) Quantitative analysis of cell proliferation with or without p53 knockdown following treatment with TMZ + Li. Scale bar $=50 \mu \mathrm{m}$. (D) Quantitative analysis of apoptotic cells based on PI incorporation and detection by flow cytometry $48 \mathrm{~h}$ after treatment with TMZ + Li and p53 knockdown. (E) Detection of apoptosis with the TUNEL assay in control and p53-deficient cells treated with TMZ + Li. Scale bar $=20 \mu \mathrm{m}$. (F) FasL expression in control and p53-deficient U87 cells treated with TMZ + Li, as determined by western blotting. Graphs show the means of triplicate samples from three independent experiments. ${ }^{\star} P<0.05,{ }^{\star} * P<0.01$.

BALB/C mice; 3 weeks later, when tumours reached a size of $150-160 \mathrm{~mm}^{3}$, mice were randomly divided into four groups $(n=8$ per group) and were administered $\mathrm{Li}, \mathrm{TMZ}, \mathrm{TMZ}+\mathrm{Li}$ or vehicle. Tumour growth was monitored by measurement with calipers (Precision Instruments Co., Shanghai, China) every 3 days. On day 42 or when tumours reached a size $>1 \mathrm{~cm}^{3}$, mice were killed using euthasol. Tumour volume $(V)$ was calculated as follows: $V=L \times W^{2} \times 0.5$, where $L$ is the length and $W$ is the width. Tumour weight was recorded at the end of the study.

Immunohistochemistry. Paraffin-embedded tumour specimens were cut into $4 \mu \mathrm{m}$ sections and sections were labelled with primary antibodies against human pSer21-GSK-3 $\alpha$ (36E9; Cell Signaling Technology) (1:100), pSer9-GSK-3 $\beta$ (5B3; Cell Signaling Technology; $1: 50)$, NFAT1 $(1: 100)$ and FasL $(1: 50)$, followed by incubation with horseradish peroxidase-labelled secondary antibody included in an immunohistochemical labelling kit (KIT-5930; MaxVision, Fu Zhou, China). Results from immunohistochemistry were quantified in a blinded fashion as previously described (Han et al, 2013). Samples were imaged under a BX-51 light microscope (Olympus).

Statistical analysis. The Student's $t$-test and one-way analysis of variance were used to evaluate the statistical significance of differences among groups. Differences in survival were analysed with the log-rank test and Kaplan-Meier analysis. Two-tailed $P$-values $<0.05$ were considered significant. Fas expression level according to TP53 status were determined from The Cancer Genome Atlas (TCGA) glioma data set (http://cancergenome.nih.gov/) as previously described (Cheng et al, 2016). SPSS v.19.0 (SPSS Inc., Chicago, IL, USA) and GraphPad Prism 6 (GraphPad Inc., San Diego, CA, USA) software were used for statistical analyses.

\section{RESULTS}

Li enhances the cytotoxicity of TMZ against GBM cells. Lowdose $\mathrm{Li}$ alone had little effect on TP53wt GBM cell viability
(Figure 1A). In contrast, TMZ suppressed MGMT-methylated U87 cell proliferation by $41.9 \%$ and MGMT-unmethylated G1 cell proliferation by $21.2 \%$; this effect was potentiated by combination with $1.2 \mathrm{~mm} \mathrm{Li}(P<0.05)$, resulting in a 70.3 and $59.8 \%$ decrease in proliferation of U87 and G1 cells, respectively (Figure 1B-D). Since there is a lag phase before cell death induced by TMZ, the viability of U87 and G1 cells was also examined 10 days after TMZ and Li treatment with the MTT assay. Li potentiated the inhibitory effect of TMZ even after a longer incubation time (Supplementary Figure S1A), including inhibition of neurosphere formation (by 3.3- to 4-fold; Figure 1E). However, the combinational effects of TMZ and Li were insignificant in TP53mut U251 and G2 cells (Supplementary Figure S1B and C).

Combined treatment with TMZ and Li leads to apoptosis of GBM cells. Li treatment did not increase the rate of cell death (Figure 1A, F and G), whereas TMZ combined with Li increased the percentage of cells with sub-G0 DNA content by 1.6- to 2.4fold relative to the TMZ-only group (Figure 1F). Furthermore, lowdose Li had a minor effect on apoptosis, as determined by annexin$\mathrm{V}$ staining and the TUNEL assay. However, the rate of apoptosis was increased by 9.3- and 2.2-fold upon TMZ administration alone in U87 and G1 cells, respectively, while combined treatment increased the rate by 9.8 - to 16 -fold (Figures $1 \mathrm{G}$ and $2 \mathrm{~A}$ ). This was accompanied by changes in nuclear morphology, a decrease in nuclear volume, chromatin condensation and nuclear fragmentation in TP53wt GBM cells (Figure 2B), which are features of dying cells. However, Li did not enhance the apoptosis-inducing effect of TMZ in TP53mut U251 and G2 cells (Supplementary Figure S1B-E).

FasL is upregulated by TMZ and Li treatment and is correlated with GSK-3 inhibition and NFAT1nuclear translocation. To investigate the mechanism by which combined $\mathrm{TMZ}$ and $\mathrm{Li}$ treatment increased TP53wt GBM cell death, we first examined GSK-3 activity by western blotting using antibodies against inactive GSK-3 (i.e., phosphorylated at serines 21 and 9 of GSK- $3 \alpha$ and $-3 \beta$, 
respectively) and those that recognise GSK- $3 \alpha / \beta$ irrespective of phosphorylation state. Treatment with TMZ or Li alone increased pGSK-3 level by 1- to 2-fold, while combined treatment had a more potent effect, inducing a 4 - to 5 -fold increase (Figure 2C).

We then examined the intracellular localisation of NFAT1 in TP53wt GBM cells by immunocytochemistry and confocal microscopy. Consistent with previous reports describing increased nuclear NFAT levels upon inhibition of GSK-3 activity (Crabtree and Olson, 2002; Gomez-Sintes and Lucas, 2010), treatment with either TMZ or Li increased NFAT1 nuclear translocation, an effect that was enhanced by combined treatment (Figure 2D). These results were confirmed by western blot analysis of cytoplasmic and nuclear proteins: total NFAT1 levels were similar in both fractions from control cells (Figure 2E-H), but were slightly reduced in the cytoplasmic fraction of TMZ- and/or Li-treated U87 (Figure 2E and F) or G1 (Figure 2G and H) cells. On the other hand, nuclear NFAT1 levels were increased after the combined treatment, resulting in a 7.7 - to 14.7 -fold increase in nuclear/cytoplasmic NFAT1 ratios.

We next investigated whether the increase in NFAT1 nuclear translocation stimulated FasL expression by real-time RT-PCR and western blotting. Consistent with our previous study (Han et al, 2013), combined treatment with TMZ and Li increased FasL expression by 36.5-47.9-fold at both the mRNA and protein levels in U87 (Figure 2I) and G1 (Figure 2J) cells. Moreover, in agreement with previous reports (Roos et al, 2007), Fas receptor expression was upregulated by 8 -9-fold in TP53wt GBM cells but not in TP53mut GBM cells upon exposure to TMZ (data not shown).

p53 status influences apoptosis induced by $\mathrm{TMZ}+\mathrm{Li}$. According to the TCGA glioma data set, TP53wt gliomas have higher Fas expression than TP53mut gliomas (Figure 3A). p53 knockdown was associated with downregulation of Fas (Figure 3B) and suppressed TMZ + Li-induced U87 cell death (Figure 3C-F). Similar results were obtained in G1 cells (data not shown). These results indicate that $\mathrm{p} 53$ status determines the apoptotic response of glioma cells to $\mathrm{TMZ}+\mathrm{Li}$.

NFAT1 knockdown attenuates GBM cell death induced by TMZ + Li. To determine whether the changes in NFAT1/FasL expression and localisation in response to $\mathrm{TMZ}+\mathrm{Li}$ treatment were responsible for TP53wt GBM cell death, we generated U87 and G1 cell lines in which NFAT1 expression was stably knocked down with specific shRNA. The downregulation of NFAT1 expression was confirmed by RT-PCR and western blotting (Figure 4A). In the absence of NFAT1 (Figure 4B), the effects of TMZ and Li on TP53wt GBM cells were attenuated relative to control cells; that is, the suppression of cell proliferation (Figure 4C and D) and induction of cell death (Figure $4 \mathrm{E}-\mathrm{G}$ ) were reduced. Moreover, FasL expression was downregulated in U87 (Figure 4H) and G1 (Figure 4I) cells treated with shRNA against NFAT1. The results were confirmed using a different shRNA targeting NFAT1
A

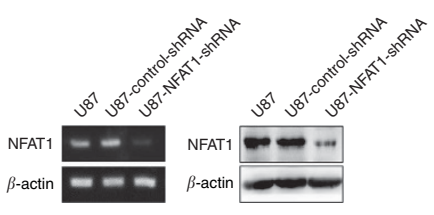

B

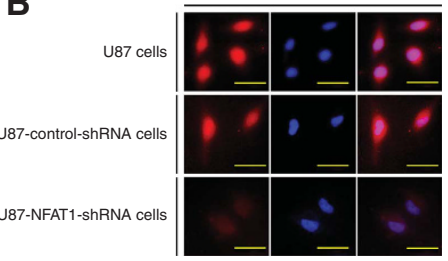

TMZ+Li treated

C
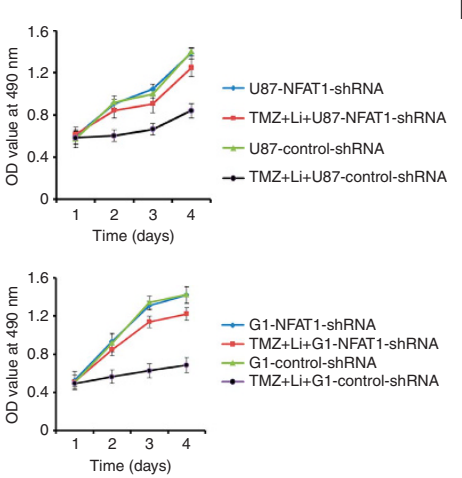

$\rightarrow$ G1-NFAT1-ShRNA

$\rightarrow$ TMZ+Li+G1-NFAT1-shRNA - G1-control-shRNA - TMZ+Li+G1-control-shRNA

E
D
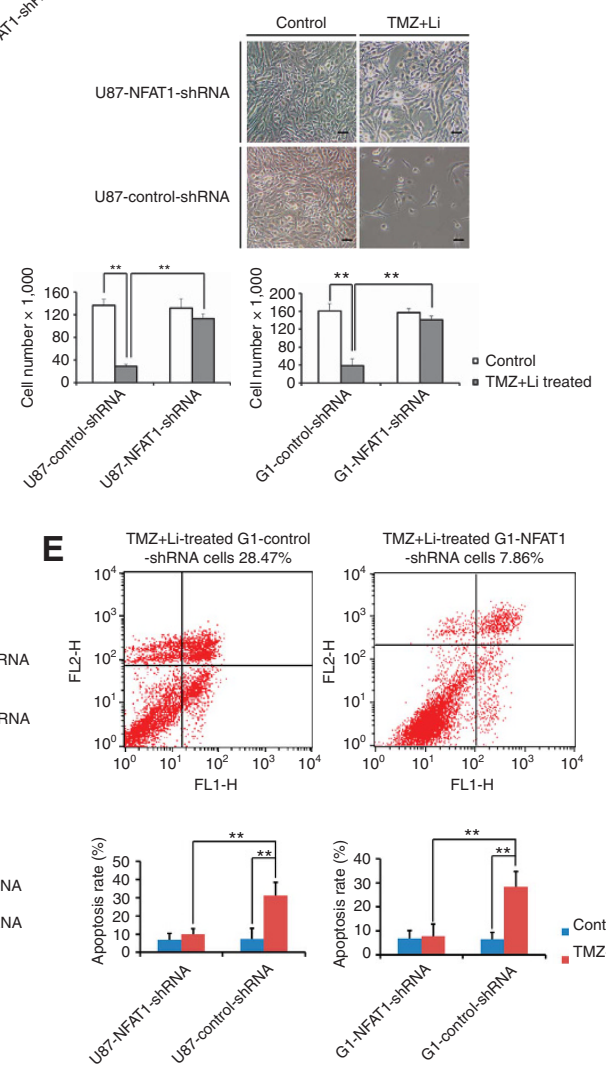

$\mathbf{F}$
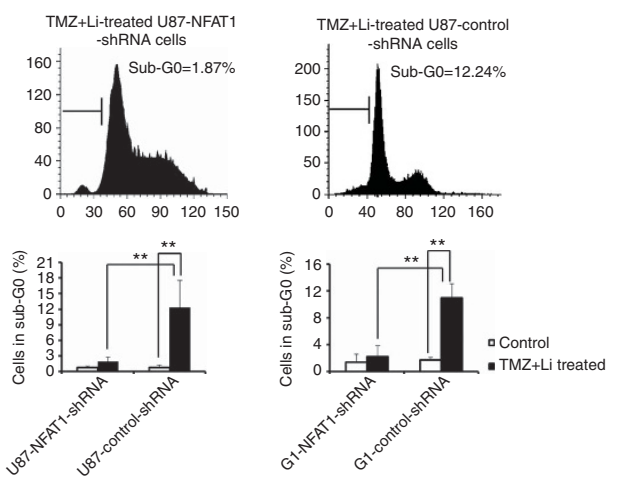

G
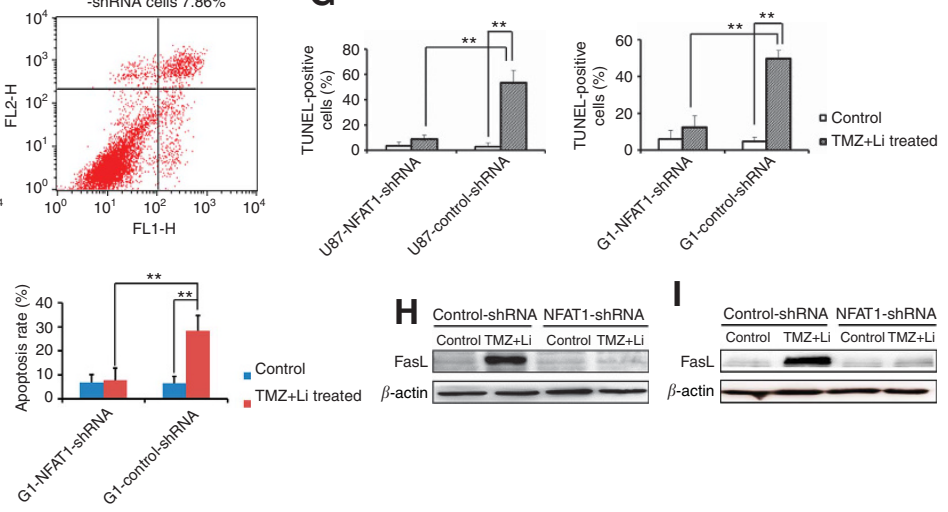

Figure 4. TMZ + Li-induced TP53wt GBM cell death is NFAT1-dependent. (A) PCR (left) and western blot (right) analyses showing knockdown of NFAT1 in U87 cells by transfection of specific shRNA. (B) Confocal micrographs of NFAT1 expression in control and NFAT1-silenced U87 cells treated with TMZ $(70 \mu \mathrm{M})+\mathrm{LiCl}(1.2 \mathrm{~mm})$, as determined by immunocytochemistry. Scale bar $=25 \mu \mathrm{m}$. (C, D) MTT assay (C) and quantitative analysis of viability (D) in control and NFAT1-silenced cells treated with TMZ + Li. Scale bar $=50 \mu \mathrm{m}$. (E, F) Analysis of cell death based on annexin-V staining (E) and incorporation of PI (F) and detection by flow cytometry. NFAT1 knockdown prevented cell death induced by TMZ + Li. (G) Results of the TUNEL assay showing the percentage of apoptotic cells in control and NFAT1-silenced cells treated with TMZ $+\mathrm{Li}$. $(\mathbf{H}, \mathbf{I}) \mathrm{Western}$ blot analysis of FasL expression in control and NFAT1-silenced U87 (H) and G1 (I) cells treated with TMZ + Li. Graphs show the means of triplicate samples from three independent experiments. ${ }^{\star} P<0.05,{ }^{* \star} P<0.01$. 


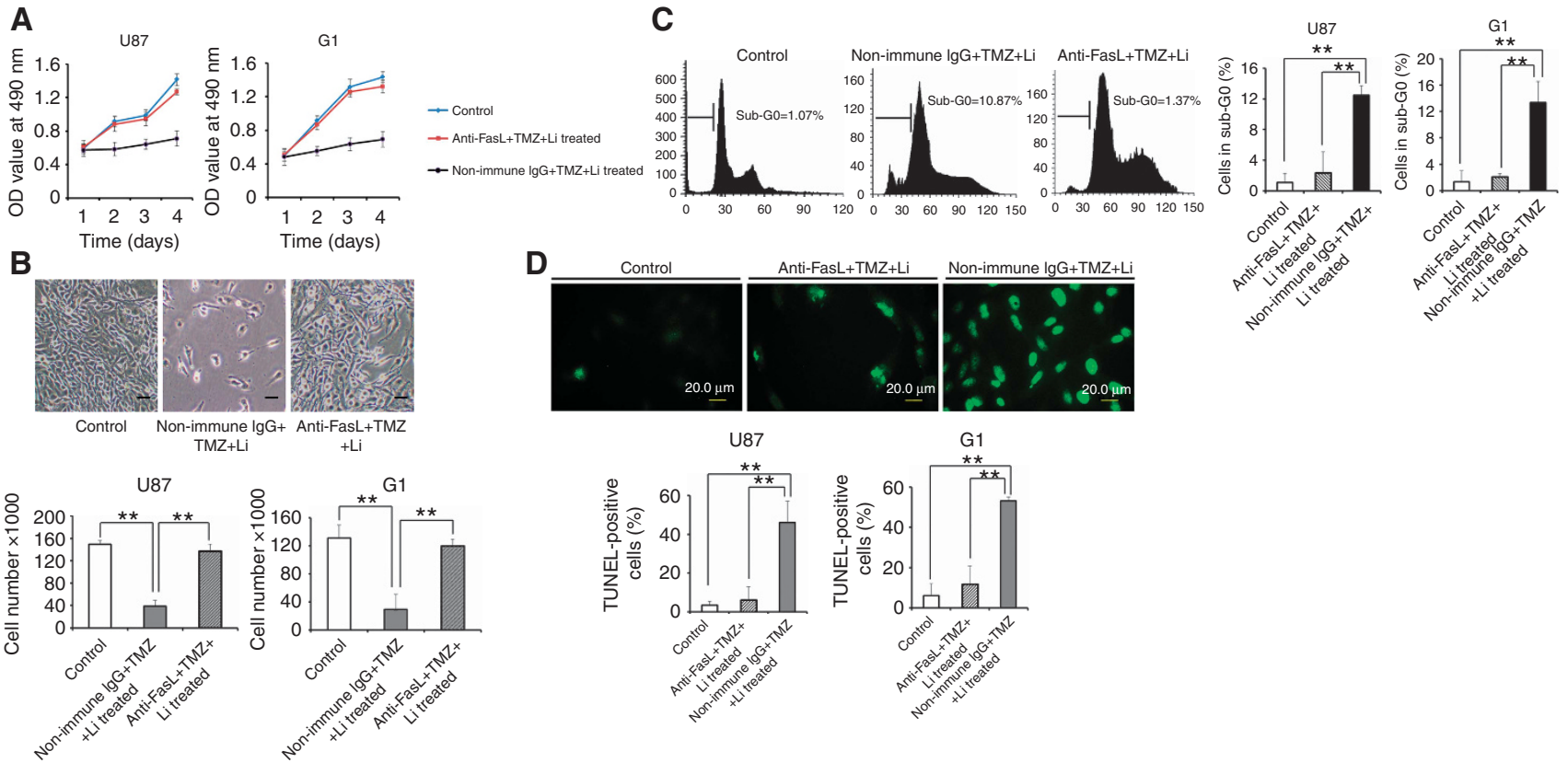

Figure 5. FasL neutralisation significantly inhibits TMZ + Li-induced TP53wt GBM cell death. (A, B) The decrease in cell viability and proliferation induced by TMZ + Li was abrogated by FasL neutralisation, as determined by the MTT assay (A) and cell counts (B). Scale bar $=50 \mu \mathrm{m}$. (C) Cell death was evaluated by flow cytometry after $48 \mathrm{~h}$ of treatment with TMZ + Li. Cells were pre-incubated with non-immune lgG or FasL neutralising antibody. The percentage of cells in the sub-G0 phase is shown in the graphs. (D) Results of the TUNEL assay showing the percentage of apoptotic control and FasL-neutralised cells treated with TMZ + Li. Graphs show the means of triplicate samples from three independent experiments. $\star P<0.05,{ }^{\star} * P<0.01$

(data not shown). These findings indicate a direct role for NFAT1 in TP53wt GBM cell death induced by TMZ + Li.

FasL neutralisation suppresses apoptosis induced by TMZ $+\mathbf{L i}$. To clarify the role of FasL in TMZ + Li-induced apoptosis, U87 and G1 cells were pre-treated with anti-FasL neutralising antibody or non-immune IgG prior to $\mathrm{TMZ}+\mathrm{Li}$ administration. FasL neutralisation inhibited $\mathrm{TMZ}+\mathrm{Li}$-induced apoptosis, as determined by the MTT and TUNEL assays, cell counts and sub-G0 analysis (Figure $5 \mathrm{~A}-\mathrm{D}$ ). These results indicate that $\mathrm{TMZ}+\mathrm{Li}$ induces TP53wt GBM cell apoptosis via NFAT1/FasL signalling.

TMZ combined with $\mathrm{Li}$ prevents tumour growth in vivo. Administration of $\mathrm{TMZ}+\mathrm{Li}$ prolonged survival in mice with intracranial tumours: the median survival times were $22 \pm 0.46$, $24 \pm 3.54$ and $31 \pm 3.53$ days for control, Li-only and TMZ-only groups, respectively (Figure $6 \mathrm{~A}$ ) and $46 \pm 2.36$ days for the $\mathrm{TMZ}+\mathrm{Li}$ group $(P<0.05, \mathrm{TMZ}+\mathrm{Li}$ vs single drug $)$. The combined treatment also reduced subcutaneous tumour growth rate; after 21 days of treatment, tumour volumes for the control, Li alone, TMZ alone and TMZ $+\mathrm{Li}$ groups were $649 \pm 198,557 \pm 165$, $364 \pm 110$ and $63 \pm 43 \mathrm{~mm}^{3}$, respectively $(P<0.001$; Figure $6 \mathrm{~B})$. The combined treatment increased the rate of apoptosis of GBM cells, as determined by the TUNEL assay (Figure 6C); moreover, it induced the upregulation of pGSK- $3 \alpha$ (Figure 6D), pGSK-3 $\beta$ (Figure 6E) and FasL (Figure 6G) and increased the nuclear translocation of NFAT1 (Figure 6F) in vivo.

\section{DISCUSSION}

Survival rates in GBM patients are low due to the poor performance of existing treatments. TMZ is widely used as the first-line drug but its efficacy is limited and transient due to the genetic heterogeneity of GBM cells (Cloughesy et al, 2014; Weller et al, 2014), leading to chemoresistance and treatment failure. Enhancing the cytotoxicity of TMZ can potentially overcome this problem. Previous studies have shown that cell death in gliomas induced by TMZ is due to apoptosis (Roos et al, 2007; Weyhenmeyer et al, 2016); however, this is dependent on TP53 status. In TP53wt GBM cells, TMZ stimulates Fas receptor expression and activates the Fas apoptotic pathway, while in TP53mut GBM cells, it triggers the intrinsic mitochondrial apoptotic pathway (Roos et al, 2007). It is conceivable that in TP53wt cells, activators of Fas/FasL signalling increase the efficacy of TMZ.

We previously found that hyperactivation of NFAT1, which is highly expressed in GBM cells, induces FasL expression and tumour cell death, mimicking AICD in mature lymphocytes (Han et al, 2013; Tie et al, 2013). In T cells, fibroblasts, and neurons, NFAT1 activation induces apoptosis (Gomez-Sintes and Lucas, 2010; Mognol et al, 2016). Although NFAT1 can act as an oncogene or a tumour suppressor depending on cell and tissue type (Mognol et al, 2016), cell death induced by NFAT1 hyperactivation has been observed in several tumours, including neuroblastoma and Burkitt's lymphoma (Alvarez et al, 2011; Robbs et al, 2013). Thus, activation of the NFAT1/FasL pathway is clinically significant in GBM. NFAT1 activity is negatively regulated by GSK-3 (Crabtree and Olson, 2002); inhibiting GSK3 activity could in turn activate NFAT1. It has been reported that inhibiting GSK-3 induces glioma cell death (Kotliarova et al, 2008; Korur et al, 2009) via activation of c-MYC (Kotliarova et al, 2008). Interestingly, c-MYC expression is regulated by NFAT1 (Mognol et al, 2012). Thus, inhibition of GSK-3 activity may lead to upregulation of c-MYC expression (Kotliarova et al, 2008) via hyperactivation of NFAT1. Moreover, as a regulator of FasL gene transcription, c-MYC-induced apoptosis requires functional FasL (Brunner et al, 2000; Kasibhatla et al, 2000; Kavurma and Khachigian, 2003). Therefore, NFAT1 hyperactivation induces c-MYC overexpression; NFAT1 and c-MYC may cooperatively upregulate FasL expression, leading to glioma cell death. These data provide evidence of a GBM cell death regulatory network involving GSK-3 and NFAT1. 
A

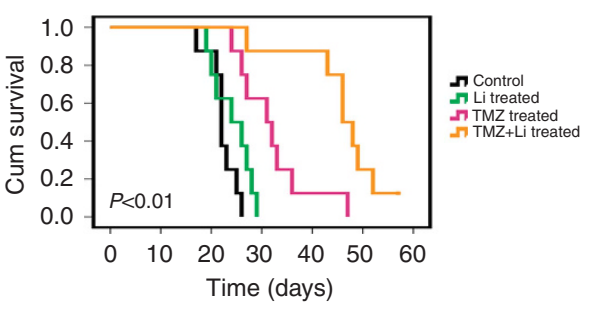

B
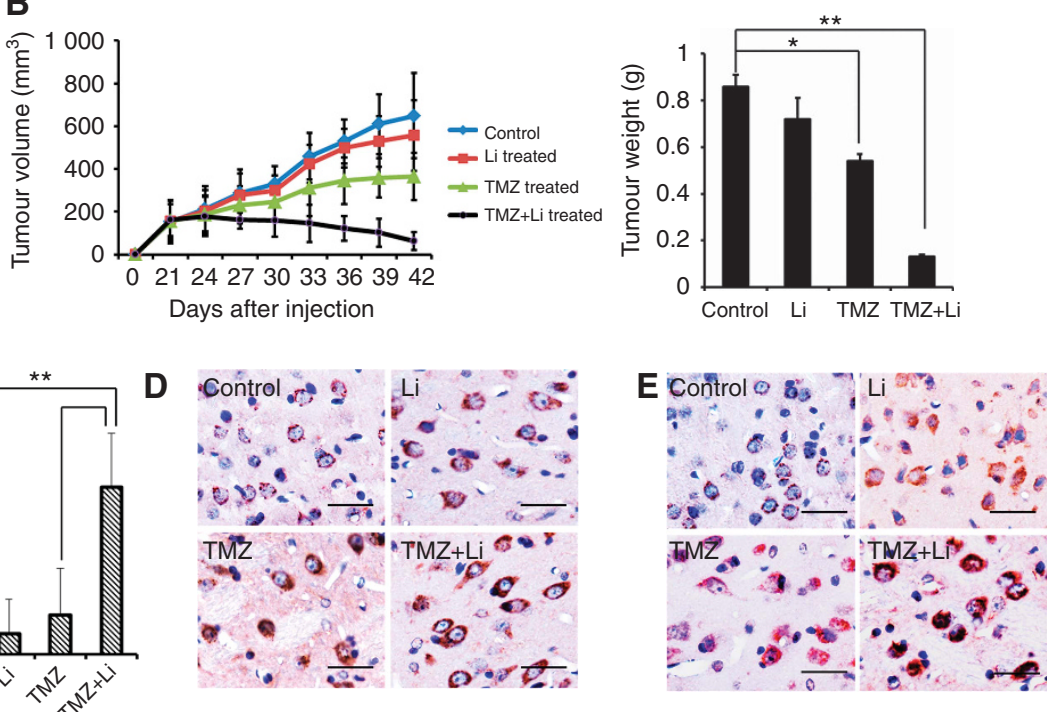
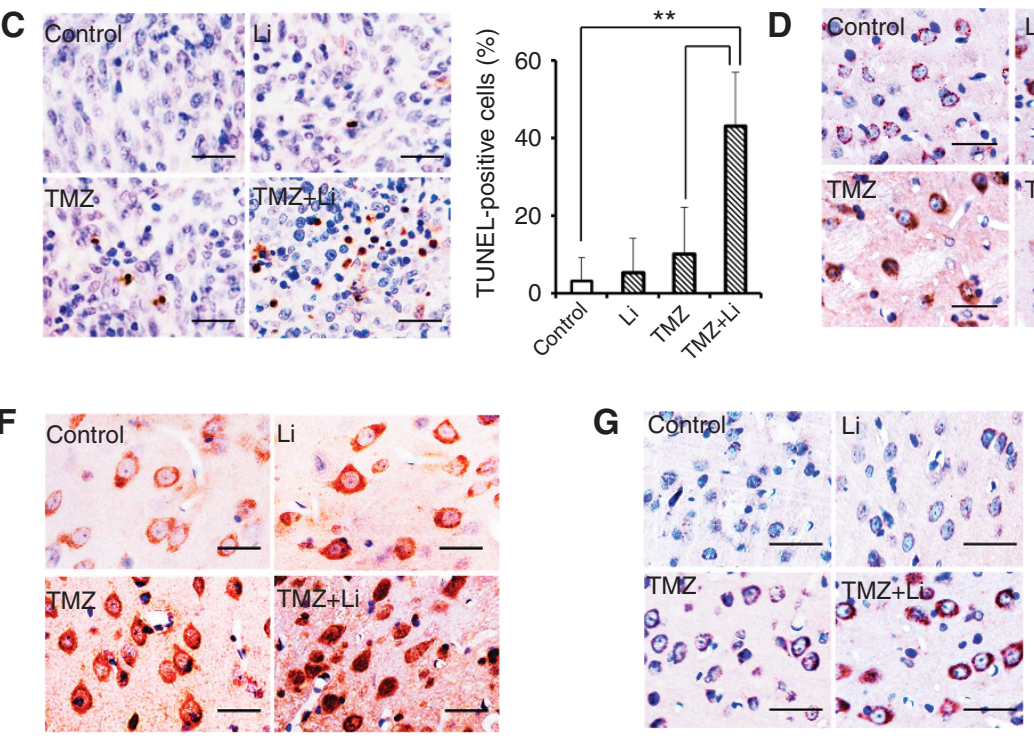

Figure 6. TMZ combined with Li inhibits tumour growth in vivo. (A) Kaplan-Meier survival plots for intracranial tumour-bearing mice treated with $\mathrm{Li}, \mathrm{TMZ}$ or TMZ + Li. The log-rank test revealed longer survival times for mice treated with $\mathrm{TMZ}+\mathrm{Li}$ as compared with those treated with either drug alone or control animals. (B) Subcutaneous tumour growth in mice treated with Li, TMZ or TMZ + Li. Tumour growth rate (left) and final tumour weight (right) were reduced by TMZ + Li treatment as compared with either drug alone or the control. (C) Results of the TUNEL assay showing induction of GBM cell death in vivo by treatment with TMZ + Li. (D-G) Immunohistochemical detection of increased pSer21-GSK-3 $\alpha$ $(\mathbf{D})$ and pSer9-GSK-3 $\beta$ (E) levels, nuclear translocation of NFAT1 (F) and FasL expression (G) in vivo by combined treatment of TMZ and Li. ${ }^{\star} P<0.05,{ }^{\star} * P<0.01$. Scale bar $=50 \mu \mathrm{m}$.

Li is an inhibitor of GSK-3 that acts via multiple signalling pathways (Young, 2009). Chronic exposure to Li inhibits GSK-3 activity, induces nuclear translocation of NFATs, increases FasL levels and leads to apoptosis in neurons (Gomez-Sintes and Lucas, 2010). Li has also been shown to decrease glioma cell invasion and proliferation via GSK-3 inhibition (Nowicki et al, 2008; Chou et al, 2012; Fu et al, 2014). However, this requires a high concentration $(>5 \mathrm{~mm}$ ), which can cause permanent brain damage (Young, 2009). Here we found that low-dose $\mathrm{Li}(1.2 \mathrm{~mm})$ alone moderately inhibited GSK-3, activated NFAT1 and upregulated FasL expression. However, consistent with previous studies (Nowicki et al, 2008; Fu et al, 2014), these effects were not sufficiently strong to alter GBM cell viability and proliferation in vitro and in vivo. Moreover, the apoptotic effect of Li-induced FasL requires adequate Fas levels. We speculated that the effects of Li could be potentiated by co-administration of a drug such as TMZ, which could activate the GSK-3/NFAT1/Fas/FasL apoptotic pathway. Although it provides a mechanistic basis of TMZ resistance, TMZ can activate AKT, resulting in phosphorylation and deactivation of GSK-3 in GBM cells (Vo et al, 2014; Yu et al, 2015). According to TCGA, Fas is expressed at higher levels in TP53wt as compared with TP53mut gliomas. We demonstrated that clinically relevant concentrations of TMZ $(70 \mu \mathrm{M})$ increased pGSK-3 and Fas levels, which resulted in nuclear translocation of NFAT1 and potentiation of the effects of Li. Furthermore, the combination of TMZ and Li significantly enhanced GBM cell death mainly through hyperactivation of NFAT1 and upregulation of Fas/FasL in vitro and in vivo.
However, we found that the combinational effect of TMZ and Li was insignificant in TP53mut U251 and primary G2 cells (Chen et al, 2016; Supplementary Figure S1). Moreover, $p 53$ knockdown reduced Fas expression and inhibited TMZ + Li-induced apoptosis in TP53wt GBM cells (Figure 3). Thus, TP53wt exerts a strong positive effect on TMZ + Li-induced Fas/FasL cell death; in its absence, TMZ may only trigger the less efficient mitochondrial apoptotic pathway that is not potentiated by Li (Roos et al, 2007).

In this study, the median survival time was 46 days for tumourbearing mice receiving combinatorial treatment, which was 15 days longer than those treated with TMZ alone; moreover, $87.5 \%$ (7 of 8) of these mice survived more than 40 days, with one $(12.5 \%)$ surviving more than 60 days. Our results are comparable to other studies of mice treated with combinatorial therapies using U87 cells that survived 4-26.5 days longer than mice treated with TMZ alone (Alonso et al, 2007; Liu et al, 2014; Kim et al, 2015; Radoul et al, 2016). However, since these studies used different strains of mice, different doses of TMZ, U87 cells with different genetic manipulations and variable end points, caution should be exercised when comparing the results.

Li has been used for over 100 years for the treatment of mood disorders and depression (Young, 2009). It is also ideal for the treatment of GBM for the following reasons. Firstly, GBM is associated with a higher risk of mood disturbance - especially depression - compared with other cancers (Rooney et al, 2011; Acquaye et al, 2013). Secondly, Li can restore white blood cells after radio- and chemotherapy and also boost immunoglobulins 
and enhance natural killer cell activity (Young, 2009). Since GBM patients are often immunocompromised after radiotherapy/chemotherapy, Li can be effective in restoring immune function.

Our results indicate that a subset of GBM patients may benefit from combined treatment with $\mathrm{Li}$ and TMZ. Li enhanced the cytotoxicity of TMZ in TP53wt tumours independent of MGMT promoter status - that is, in MGMT-methylated U87 and MGMTunmethylated G1 cells, although U87 cells were more sensitive than G1 cells to TMZ treatment (Figure 1). According to data from TCGA and our patient cohort (63 GBM cases), $71.4-85.2 \%$ of GBMs are TP53wt. Consistent with previous reports (Brennan et al, 2013), both data sets revealed that TP53wt GBMs often harbour non-mutated IDH, non-mutated ATRX and mutated TERT promoters (Supplementary Table S3), all of which predict unfavourable prognosis. Although the relationship between TP53 status and radiotherapy/chemotherapy sensitivity is still debated (Dinca et al, 2008; Kang et al, 2011), our therapeutic approach could potentially benefit the more than two-thirds of GBM patients harbouring TP53wt (Ohgaki and Kleihues, 2007; Dinca et al, 2008).

\section{CONCLUSION}

Temozolomide and low-dose Li potently activated NFAT1/FasL signalling and induced TP53wt GBM cell death in vitro and in vivo. The combination of these two drugs could thus represent a novel therapeutic strategy for treating a subset of GBM patients.

\section{ACKNOWLEDGEMENTS}

We thank Jingpu Shi at the Department of Clinical Epidemiology, The First Affiliated Hospital of China Medical University, for assistance with statistical and survival analyses. This work was supported by grants from the National High Technology Research and Development Program of China (863) (no. 2012AA02A508), the National Natural Science Foundation of China (nos. 81472360 and 81402045) and the Science and Technology Department of Liaoning Province (no. 2011225034).

\section{CONFLICT OF INTEREST}

The authors declare no conflict of interest.

\section{REFERENCES}

Acquaye AA, Vera-Bolanos E, Armstrong TS, Gilbert MR, Lin L (2013) Mood disturbance in glioma patients. J Neurooncol 113: 505-512.

Alonso MM, Gomez-Manzano C, Jiang H, Bekele NB, Piao Y, Yung WK, Alemany R, Fueyo J (2007) Combination of the oncolytic adenovirus ICOVIR-5 with chemotherapy provides enhanced anti-glioma effect in vivo. Cancer Gene Ther 14: 756-761.

Alvarez S, Blanco A, Fresno M, Munoz-Fernandez MA (2011) TNF-alpha contributes to caspase-3 independent apoptosis in neuroblastoma cells: role of NFAT. PLoS One 6: e16100.

Aras Y, Erguven M, Aktas E, Yazihan N, Bilir A (2016) Antagonist activity of the antipsychotic drug lithium chloride and the antileukemic drug imatinib mesylate during glioblastoma treatment in vitro. Neurol Res 38: 766-774.

Ayton S, Lei P (2012) The Abeta-induced NFAT apoptotic pathway is also activated by GSK-3 inhibition: implications for Alzheimer therapeutics. J Neurosci 32: 9454-9456.

Brennan CW, Verhaak RG, McKenna A, Campos B, Noushmehr H, Salama SR, Zheng S, Chakravarty D, Sanborn JZ, Berman SH, Beroukhim R, Bernard B, Wu CJ, Genovese G, Shmulevich I, Barnholtz-Sloan J, Zou L, Vegesna R, Shukla SA, Ciriello G, Yung WK, Zhang W, Sougnez C, Mikkelsen T,
Aldape K, Bigner DD, Van Meir EG, Prados M, Sloan A, Black KL, Eschbacher J, Finocchiaro G, Friedman W, Andrews DW, Guha A, Iacocca M, O’Neill BP, Foltz G, Myers J, Weisenberger DJ, Penny R, Kucherlapati R, Perou CM, Hayes DN, Gibbs R, Marra M, Mills GB, Lander E, Spellman P, Wilson R, Sander C, Weinstein J, Meyerson M, Gabriel S, Laird PW, Haussler D, Getz G, Chin L (2013) The somatic genomic landscape of glioblastoma. Cell 155: 462-477.

Brunner T, Kasibhatla S, Pinkoski MJ, Frutschi C, Yoo NJ, Echeverri F, Mahboubi A, Green DR (2000) Expression of Fas ligand in activated T cells is regulated by c-Myc. J Biol Chem 275: 9767-9772.

Chen L, Jiang Z, Ma H, Ning L, Chen H, Li L, Qi H (2016) Volatile oil of Acori graminei rhizoma-induced apoptosis and autophagy are dependent on p53 status in human glioma cells. Sci Rep 6: 21148.

Cheng W, Ren X, Zhang C, Cai J, Liu Y, Han S, Wu A (2016) Bioinformatic profiling identifies an immune-related risk signature for glioblastoma. Neurology 86: 2226-2234.

Chou CH, Chou AK, Lin CC, Chen WJ, Wei CC, Yang MC, Hsu CM, Lung FW, Loh JK, Howng SL, Hong YR (2012) GSK3beta regulates Bcl2L12 and Bcl2L12A anti-apoptosis signaling in glioblastoma and is inhibited by LiCl. Cell Cycle 11: 532-542.

Cloughesy TF, Cavenee WK, Mischel PS (2014) Glioblastoma: from molecular pathology to targeted treatment. Annu Rev Pathol 9: 1-25.

Crabtree GR, Olson EN (2002) NFAT signaling: choreographing the social lives of cells. Cell 109(Suppl): S67-S79.

Diaz-Meco MT, Lallena MJ, Monjas A, Frutos S, Moscat J (1999) Inactivation of the inhibitory kappaB protein kinase/nuclear factor kappaB pathway by Par-4 expression potentiates tumor necrosis factor alpha-induced apoptosis. J Biol Chem 274: 19606-19612.

Dinca EB, Lu KV, Sarkaria JN, Pieper RO, Prados MD, Haas-Kogan DA, Vandenberg SR, Berger MS, James CD (2008) p53 Small-molecule inhibitor enhances temozolomide cytotoxic activity against intracranial glioblastoma xenografts. Cancer Res 68: 10034-10039.

Fu Y, Zheng Y, Chan KG, Liang A, Hu F (2014) Lithium chloride decreases proliferation and migration of C6 glioma cells harboring isocitrate dehydrogenase 2 mutant via GSK-3beta. Mol Biol Rep 41: 3907-3913.

Gomez-Sintes R, Lucas JJ (2010) NFAT/Fas signaling mediates the neuronal apoptosis and motor side effects of GSK-3 inhibition in a mouse model of lithium therapy. J Clin Invest 120: 2432-2445.

Han S, Li X, Qiu B, Jiang T, Wu A (2015) Can lateral ventricle contact predict the ontogeny and prognosis of glioblastoma. J Neurooncol 124: 45-55.

Han S, Li Z, Master LM, Master ZW, Wu A (2014) Exogenous IGFBP-2 promotes proliferation, invasion, and chemoresistance to temozolomide in glioma cells via the integrin betal-ERK pathway. Br J Cancer 111: 1400-1409.

Han S, Tie X, Meng L, Wang Y, Wu A (2013) PMA and ionomycin induce glioblastoma cell death: activation-induced cell-death-like phenomena occur in glioma cells. PLoS One 8: e76717.

Han S, Xia J, Qin X, Han S, Wu A (2013) Phosphorylated SATB1 is associated with the progression and prognosis of glioma. Cell Death Dis 4: e901.

Johanns TM, Fu Y, Kobayashi DK, Mei Y, Dunn IF, Mao DD, Kim AH, Dunn GP, AUID-Oho (2016) High incidence of TERT mutation in brain tumor cell lines. Brain Tumor Pathol 33: 222-227.

Kang HC, Kim CY, Han JH, Choe GY, Kim JH, Kim JH, Kim IA (2011) Pseudoprogression in patients with malignant gliomas treated with concurrent temozolomide and radiotherapy: potential role of $\mathrm{p} 53$ J Neurooncol 102: 157-162.

Kasibhatla S, Beere HM, Brunner T, Echeverri F, Green DR (2000) A 'noncanonical' DNA-binding element mediates the response of the Fas-ligand promoter to c-Myc. Curr Biol 10: 1205-1208.

Kavurma MM, Khachigian LM (2003) Signaling and transcriptional control of Fas ligand gene expression. Cell Death Differ 10: 36-44.

Kim SS, Rait A, Kim E, Pirollo KF, Chang EH (2015) A tumor-targeting p53 nanodelivery system limits chemoresistance to temozolomide prolonging survival in a mouse model of glioblastoma multiforme. Nanomedicine 11: 301-311.

Korur S, Huber RM, Sivasankaran B, Petrich M, Morin Jr P, Hemmings BA, Merlo A, Lino MM (2009) GSK3beta regulates differentiation and growth arrest in glioblastoma. PLoS One 4: e7443.

Kotliarova S, Pastorino S, Kovell LC, Kotliarov Y, Song H, Zhang W, Bailey R, Maric D, Zenklusen JC, Lee J, Fine HA (2008) Glycogen synthase kinase-3 inhibition induces glioma cell death through c-MYC, nuclear factorkappaB, and glucose regulation. Cancer Res 68: 6643-6651. 
Kovacsics CE, Gottesman, Gould TD (2009) Lithium's antisuicidal efficacy: elucidation of neurobiological targets using endophenotype strategies. Annu Rev Pharmacol Toxicol 49: 175-198.

Law ME, Templeton KL, Kitange G, Smith J, Misra A, Feuerstein BG, Jenkins RB (2005) Molecular cytogenetic analysis of chromosomes 1 and 19 in glioma cell lines. Cancer Genet Cytogenet 160: 1-14.

Li H, Alonso-Vanegas M, Colicos MA, Jung SS, Lochmuller H, Sadikot AF, Snipes GJ, Seth P, Karpati G, Nalbantoglu J (1999) Intracerebral adenovirus-mediated p53 tumor suppressor gene therapy for experimental human glioma. Clin Cancer Res 5: 637-642.

Liu HL, Huang CY, Chen JY, Wang HY, Chen PY, Wei KC (2014) Pharmacodynamic and therapeutic investigation of focused ultrasoundinduced blood-brain barrier opening for enhanced temozolomide delivery in glioma treatment. PLoS One 9: e114311.

Mognol GP, Carneiro FR, Robbs BK, Faget DV, Viola JP (2016) Cell cycle and apoptosis regulation by NFAT transcription factors: new roles for an old player. Cell Death Dis 7: e2199.

Mognol GP, de Araujo-Souza PS, Robbs BK, Teixeira LK, Viola JP (2012) Transcriptional regulation of the c-Myc promoter by NFAT1 involves negative and positive NFAT-responsive elements. Cell Cycle 11: 1014-1028.

Nowicki MO, Dmitrieva N, Stein AM, Cutter JL, Godlewski J, Saeki Y, Nita M, Berens ME, Sander LM, Newton HB, Chiocca EA, Lawler S (2008) Lithium inhibits invasion of glioma cells; possible involvement of glycogen synthase kinase-3. Neuro Oncol 10: 690-699.

Ohgaki H, Kleihues P (2007) Genetic pathways to primary and secondary glioblastoma. Am J Pathol 170: 1445-1453.

Radoul M, Chaumeil MM, Eriksson P, Wang AS, Phillips JJ, Ronen SM (2016) MR studies of glioblastoma models treated with dual PI3K/mTOR inhibitor and temozolomide: metabolic changes are associated with enhanced survival. Mol Cancer Ther 15: 1113-1122.

Robbs BK, Lucena PI, Viola JP (2013) The transcription factor NFAT1 induces apoptosis through cooperation with Ras/Raf/MEK/ERK pathway and upregulation of TNF-alpha expression. Biochim Biophys Acta 1833: 2016-2028.

Rooney AG, Carson A, Grant R (2011) Depression in cerebral glioma patients: a systematic review of observational studies. J Natl Cancer Inst 103: 61-76.

Roos WP, Batista LF, Naumann SC, Wick W, Weller M, Menck CF, Kaina B (2007) Apoptosis in malignant glioma cells triggered by the temozolomide-induced DNA lesion O6-methylguanine. Oncogene 26 186-197.

Stupp R, Mason WP, van den Bent MJ, Weller M, Fisher B, Taphoorn MJ, Belanger K, Brandes AA, Marosi C, Bogdahn U, Curschmann J, Janzer RC, Ludwin SK, Gorlia T, Allgeier A, Lacombe D, Cairncross JG, Eisenhauer E, Mirimanoff RO (2005) Radiotherapy plus concomitant and adjuvant temozolomide for glioblastoma. N Engl J Med 352: 987-996.

Tie X, Han S, Meng L, Wang Y, Wu A (2013) NFAT1 is highly expressed in, and regulates the invasion of, glioblastoma multiforme cells. PLoS One 8: e66008.

Vo VA, Lee JW, Lee HJ, Chun W, Lim SY, Kim SS (2014) Inhibition of JNK potentiates temozolomide-induced cytotoxicity in U87MG glioblastoma cells via suppression of Akt phosphorylation. Anticancer Res 34: 5509-5515.

Weller M, van den Bent M, Hopkins K, Tonn JC, Stupp R, Falini A, Cohen-Jonathan-Moyal E, Frappaz D, Henriksson R, Balana C, Chinot O, Ram Z, Reifenberger G, Soffietti R, Wick W (2014) EANO guideline for the diagnosis and treatment of anaplastic gliomas and glioblastoma. Lancet Oncol 15: e395-e403.

Weyhenmeyer BC, Noonan J, Wurstle ML, Lincoln FA, Johnston G, Rehm M, Murphy BM (2016) Predicting the cell death responsiveness and sensitization of glioma cells to TRAIL and temozolomide. Oncotarget 7: 61295-61311.

Wu N, Lin X, Zhao X, Zheng L, Xiao L, Liu J, Ge L, Cao S (2013) MiR-125b acts as an oncogene in glioblastoma cells and inhibits cell apoptosis through p53 and p38MAPK-independent pathways. Br J Cancer 109 $2853-2863$.

Young W (2009) Review of lithium effects on brain and blood. Cell Transplant 18: 951-975.

Yu Z, Zhao G, Xie G, Zhao L, Chen Y, Yu H, Zhang Z, Li C, Li Y (2015) Metformin and temozolomide act synergistically to inhibit growth of glioma cells and glioma stem cells in vitro and in vivo. Oncotarget 6 : 32930-32943.

This work is published under the standard license to publish agreement. After 12 months the work will become freely available and the license terms will switch to a Creative Commons AttributionNonCommercial-Share Alike 4.0 Unported License.

Supplementary Information accompanies this paper on British Journal of Cancer website (http://www.nature.com/bjc) 